\title{
Sobre el español del siglo XVI*
}

Félix Bugueño Miranda**

RESUMEN: El siglo XVI representa para la historia del español un hito de singular importancia, no sólo por los cambios y fijaciones en sus sistemas gramatical y fonológico, sino que también por las contribuciones léxicas de origen tan diversa que recibe.

\section{Introducción}

El siglo XVI representa para la historia de la lengua española una cesura de importancia vital. De una parte, el español alcanza un grado de evolución tal, que se convierte no sólo en una "lengua nacional", sino que dado, repetimos, su desarrollo, se hace un "producto cultural exportable", al punto que despierta gran interés en el seno de otras comunidades idiomáticas de Europa. Por otro lado, la "scientia nova" que comienza a evidenciarse a mediados del s. XV traerá como consecuencia directa un (re)descubrimiento de toda una tradición de saber greco-latino, de tal manera que la producción bibliográfica helénico-latina se convertirá en guía (y modelo) de la producción bibliográfica del $\mathrm{s}$. XVI, razón por la cual una ingente cantidad de material léxico (latino - y en parte griego -) preservado del cam-

\footnotetext{
* Recebido para publicação em maio de 2000.

**Professor Visitante DLA/Universidade Estadual de Santa Cruz, théus.
} 
bio lingüístico se incorporará a la lengua nacional española. No podemos dejar de mencionar tampoco el aporte de otras lenguas románicas al español, toda vez que por esta época se produce algo así como una "internacionalización del saber". Finalmente, las nuevas realidades de América, verbalizadas y percibidas en un muy diverso grado - es verdad -, constituirán otro rasgo que caracterizará al español de aquella centuria.

En resumen, en largo y lento proceso de desarrollo unas tendencias, de súbita aparición otras, lo cierto es que el s. XVI representa una sugestiva confluencia de contribuciones léxicas que permitirán darle al español una fisonomía propia.

Podría decirse, entonces, que esta centuria termina por consolidar unas tendencias evolutivas del léxico español. Por otra parte, el Renacimiento implicará una renovación del vocabulario, que irá a buscarse en las lenguas clásicas. Finalmente, las nuevas realidades americanas implicarán una revolución, al incorporarse a esta lengua un universo léxico nuevo y necesario para "la aclimatación" de la lengua al otro lado del océano.

\section{Esbozo cronológico de las contribuciones léxicas al español}

De todo lo dicho hasta aquí se desprende que el llamado fondo léxico patrimonial español está compuesto en su gran mayoría por el caudal léxico que el español heredó del latín. Muchos estudiosos suman a este caudal léxico algunos vestigios de las llamadas lenguas prerromanas, esto es, las lenguas que se hablaban en la Hispania antes de la llegada de los romanos a la Península (cfr., p.ej., LAPESA, 1981, cap. I; ENTWISTLE, 1982, cap. I; PENNY, 1992, cap. II). La preocupación por este sustrato léxico es legítima, puesto que no cabe "preguntarle" al latín por palabras como los topónimos de origen fenicio Cádiz (en español a través del árabe y después del latín) y Málaga; de origen celta, por otra parte, son el topónimo Sigüenza y 
palabras como álamo, brío, breña y gancho. A este grupo hay que agregar también la contribución del vasco, la misteriosa lengua de los Pirineos que ha sido la única en oponer resistencia real a la romanización. De esta lengua provienen palabras como izquierdo, arroyo, ascua, cama y sapo.

De otra parte, sin embargo, es también discutible su inclusión como contribución léxica al español, puesto que la mayoría de estas palabras se incorporó primero al latín peninsular. En todo caso, el tema es controversia constante entre los romanistas. Hay quienes como BALDINGER (1972) o PFISTER (1983) consideran que, teniendo las lenguas románicas una base tan sólida de estudios como el latín', no es de importancia inmediata preocuparse por las contribuciones léxicas hechas a éste por otras lenguas. Otro grupo de estudiosos, entre los cuales destaca Hubschmid ${ }^{2}$ (por ejemplo, HUBSCHMID, 1982), piensa lo contrario. Es bueno recordar en este sentido que la ausencia de atestiguaciones directas lleva a veces a elocubraciones no siempre respetadas por la comunidad científica. Este es el caso del sorotáptico, supuesta lengua prerromana descubierta por Corominas.

Hacia el s. IX o X ya no puede seguir llamándose de latín (clásico) o de latín tardío a la lengua de las distintas comunidades de la Romania. Es por eso que el Concilio de Tours (813) recomienda el empleo de la

\footnotetext{
'En realidad, los romanistas fundan su objeto de investigación en una paradoja. Todos los interesados en el tema suelen decir que las lenguas románicas provienen del latin. Una afirmación de esta naturaleza necesita, empero, de una cierta matización. Al hablar de "latin", esta expresión es meramente referencial. Por un lado, ella refiere normalmente a una realización dentro del diasistema que se encontraba vigente hacia el s. II a.C., cl llamado "sermo nobilis", concebido y elevado dentro de la comunidad lingüistica romana a la categoria de norma ejemplar, o sea, un modelo digno de ser imitado. Por otro lado, son los propios romanistas quienes a partir del s. XIX se han encargado de aclarar que las lenguas románicas no provienen de esta variedad de la lengua (llamémosla asi), sino que de otra bastante diferente, a la que se la llamado de "latin vulgar", y de la que, paradójicamente, se conocen sólo testimonios fragmentarios ( los "graffities" de Pompeya o las atestiguaciones del Appendix Probi, por ejemplo). Un buen panorama del latin vulgar lo ofrece VÄÄNÄNEN (1975).

'Johannes Hubschmid (1916-1995) puede ser considerado una de las mayores autoridades en el (arduo) problema de los sustratos prerromanos. Una bibliogralia completa de sus trabajos puede encontrarse en WINCKELMANN/BRAISCH (1982); addenda bibliogrática en BALDINGER (1995).
} 
"rustica romana lingua" en lugar de latín durante las homilías (más detalles se pueden encontrar en ILARI (1997), en especial cap. X a XIII). Los Juramentos de Estrasburgo (842), los documentos castellanos del 900, y, más tardíamente, la Cantiga da Guaravaia (h. 1189) nos dan testimonio de ello. Desde el punto de vista lingüístico cabe resaltar que hito importante para la Península antes de esta fecha lo son las invasiones germánicas, más precisamente las visigóticas (409); esta ocupación durará exactamente 3 siglos, y terminará con otra invasión que no podemos calificar sino de "benéfica" para la cultura de occidente. Vestigios léxicos de la presencia germánica en la Península son las palabras marca, estribo, estribar, guerra y galano (para un estudio más detallado véase PENNY, 1992, cap. IV).

De mucho mayor relevancia para el español serán las invasiones árabes que comienzan el año 711. Estas invasiones serán graduales llegando a su máxima penetración en los siglos XI y XII. Lo importante aquí es destacar que la presencia árabe en España no se restringe solamente a una empresa militar y política, sino que constituye también una empresa cultural, puesto que estos pueblos del Oriente Medio llegaron a la Península para quedarse, por lo que trajeron también todo su acervo cultural, incluido el conocimiento. Los 7 siglos de dominación árabe han dejado una huella marcante en el léxico del español. Se calcula en 4000 el número de palabras de este origen, entre primitivos y derivados. Arabismos son achaque $(<1224>$ COROMINAS, 1973 s.v. [ár. a šs-šaka, KIESLER, 1994, s.v.]) $)^{3}$, aduana (<h.1260> COROMINAS, 1973, s.v. [ár. ad-diwan, KIESLER, 1994, s.v.]), ajedrez (<h.1250> COROMINAS, 1973, s.v. [ár $a \check{s}-$ sitrang, KIESLER, 1994, s. v.]), ajuar (<h.1140> COROMINAS,

\footnotetext{
'De acuerdo con la práctica común de la Escuela de Basilea (Wartburg), cada ejemplo va seguido de la primera atestiguación, su fuente, el étimo y la autoridad que hemos considerado en nuestra decisión. Para respetar las nomas de la revista hemos tomado las siguientes decisiones: la primera documentación va entre $<>$; la luente, entre (), según las mismas normas (nos hemos tomado la libertad de no escribir por entero tres referencias bibliográficas -BB 1987, DRAE 1992 y LSJ 1990-, ya que estas abreviaturas son de uso corriente); finalmente, las referencias etimológicas van entre [ ], para no "cargar" tanto el texto con un mismo tipo de signo.
} 
1973, s.v. [ár. ǎ́šsuwar, KIESLER, 1994, s.v.]) y rehén (<s. XIII> COROMINAS, 1973, s.v. [ár. vulgar o hispanoárabe (ar-)rahán, KIESLER, 1994, s.v. $r a h n)^{4}$. Sería conveniente detenerse un momento para comentar un hecho que tal vez algún lector haya notado: En español hay un al alto número de palabras de origen árabe que comienzan por $a$-. DAWABE (1973) - imprescindible consultar también DOZY/ENGELMANN (1965) o EGUILAZ (1886); v. ahora también KIESLER (1994) - registra 1748 artículos léxicos, de los cuales 824 comienzan por esta letra (a estos registros léxicos hay que agregar los derivados, no contemplados en este lexicón: de achaque, achacoso; de aduana, aduanero; de ajedrez, ajedrecista). Esta acorresponde al artículo definido y el hecho se debe a que el árabe concibe los sustantivos sólo de manera concreta (por eso no existe artículo indefinido), de tal manera que cuando se refiere esta categoría nominal hay que hacerlo también de manera concreta, es decir, no se puede hablar de "una achicoria", sino de "la achicoria". El fenómeno de anteponer el artículo al sustantivo se conoce como "aglutinación del artículo" (cfr. SOLÁ-SOLÉ, 1968) .

La Península puede considerarse privilegiada, pues es a través de este territorio que Europa accedió a una tradición cultural y científica superior y que fue la única que pudo servir de contrapeso a la latina o a la griega, relegada en esos tiempos a un grupo muy reducido de individuos. La penetración idiomática fue de tal envergadura que el latín "prestó" palabras al árabe, devolviéndolas éste después, algo transformadas, eso sí. Este es el caso de alcázar, del lat. castra, -

\footnotetext{
"A esta lista de contribuciones árabes al romance hispánico medieval deben agregarse algunas otras que se documentan en el siglo XVI: achicoria (<1590> COROMINAS, 1973, s.v.), alicates (<1585> COROMINAS, 1973 , s.v.) y irrafa (<1570> COROMINAS, 1973, s.v.). De estas tres palabras, sólo para iirafa (COROMINAS, 1973, s.v.) olrece una imputación explicita; sin embargo, creenos que las otras dos palabras deben haber entrado también por vía culta al español.

${ }^{3}$ Según LÜDTKE (1974 : 83-84) es notoria la preservación del articulo en el iberorronance (y el portugués), asi como su ausencia en préstamos árabes en el francés y el italiano. Estal dilerencia cstriba en la intensidad y "calidad" de la penetración árabe en la Península lbérica, una penetración que fue directa, mientras que en francés e italiano este fenómeno fue "indirecto", por via del comercio.
} 
orum 'campamento o fortificación militar'. Otro fenómeno que indudablemente debe haber favorecido los préstamos del árabe al romance y a otras lenguas fue la fuerte actividad de traducción que caracterizó a la Baja Edad Media. No debe pensarse sólo en el valiosísimo aporte de Alfonso X El Sabio (1221-1284) y su Escuela de Traductores de Toledo, sino que también en la actividad de traducción arábigo-latina. Según LÜDTKE (1974: 85), en estas tareas participaban normalmente tres personas: una que leía el texto en árabe; otra que hacía al romance la traducción de lo oído y, finalmente, una tercera que traducía para el latín. En estas condiciones, no es extraño que por la falta de designaciones apropiadas (el problema de Wörter und Sachen ${ }^{6}$ ), parte de este material léxico haya pasado directamente al latín, siendo "redescubierto" después durante el Renacimiento. Tal vez eso explique por qué palabras como achicoria (<1590> COROMINAS, 1973, s.v.) o alicates ( $<1585>$ COROMINAS, 1973, s.v.) aparezcan documentadas en español casi dos siglos después de que el gran influjo árabe ha terminado. En otros casos, fue la actividad comercial la que permitió la "importación" de arabismos en las diversas lenguas. Éste es el caso del alemán Giraffe (<segunda mitad s. XIV> MACKENSEN, 1988 , s.v.), préstamo del italiano giraffa (<s. XIII> PIANIGIANI, 1990 , s.v.). El inglés girafe, por otro lado, ofrece dataciones parecidas a las del alemán, sólo que el préstamo se hizo a través del francés cfr. COD (1995, s.v.) - que, a su vez, proviene del italiano, y éste del árabe.

Esta época es también una época de grandes peregrinaciones que vienen desde el otro lado de los Pirineos. Así es como el español recibe también una apreciable contribución de galicismos (palabras de origen francés) y de occitanismos (lengua del sur de Francia que tuvo un fuerte desarrollo en la Edad Media, pero que casi desaparece en los tiempos modernos. Se la conoce también como "provenzal" ).

\section{"palabras y cosas'.}

${ }^{7}$ Es indispensable dejar en claro, sin embargo, que más modernamente existe la tendencia a entender el provenzal como una subdivisión dialectal del occitano. Cir. BUBMANN (1990, s.v. Ok-itanisch). Para una valoración del aporte cultural (y lingaístico) del occitano en la Edad Media v. LAUSBERG (1969, \$12-13). 
Estos préstamos son una consecuencia "natural" de la gran cantidad de romeros de aquellos lugares que se dirigían a Santiago de Compostela. Muchos de estos peregrinos terminaron por asentarse en la ruta que llevaba a este lugar y que se conoce con el nombre de Camino de Santiago. Según PENNY (1992, cap.IV.8) a partir del s. XI los préstamos franceses (fr.) y occitanos (occ.) se dejan sentir en campos léxicos tales como el político-militar: estandarte $<$ h.1260> (fr.), flecha <1397> (fr.), galope <s.XIII> (fr.) y el religioso: capellán $<1127>$ (occ.), deán <1192> (fr.), fraile <1187> (occ. $)^{8}$. También se encuentran palabras de este origen en los campos léxicos de la vida feudal y la vida hogareña.

Con el advenimiento del s. XIII se produce la primera avalancha de proporciones en lo que a cultismos se refiere, sobre todo, como no podría ser de otra forma, en el campo léxico religioso. Algunos de estos préstamos del latín fueron, a su vez, préstamos del griego en aquella lengua. Ejemplos de esta contribución son: ángel (lat. angelus [GEORGES, 1988, s.v.], gr. ággeloV, ${ }^{9}$ [LSJ 1990, s.v.]), apóstol (lat. apostolus [GEORGES, 1988, s.v.], gr. apostoloV ${ }^{10}$ [LSJ 1990, s.v.]), iglesia (lat. ecclesia [GEORGES, 1988, s.v.], gr. ekklhsia" [LSJ 1990, s.v.]). Préstamos propiamente latinos son cruz (lat. crux [GEORGES, 1988, s.v.], gracia (lat. gratia [GEORGES, 1988, s.v.]) e imagen (lat. imago [GEORGES, 1988, s.v.]).

El siglo XIII, por tanto, es interesante para nuestras reflexiones, ya que, producto de este "intercambio internacional" que experimenta la Península - galicismos, occitanismos, catalanismos (manjar) -, comienza también lentamente a recobrarse la preocupación por la actividad intelectual, no sólo en los territorios romances hispánicos, sino que también en otras latitudes (luego volveremos

"Podrian agregarse también herejia $<1220>$ (occ.) y hereje <1220> (occ.); ctr. MESSNER (1979: 54).

"Por una limitación del procesador de textos utilizado, no nos ha sido posible marcar el spiritus lenis en /a/ "Spiritus lenis en $/ \mathrm{a} /$.

${ }^{1 " S p i r i t u s ~ l e n i s ~ e n ~ / e / . ~}$ 
brevemente sobre este particular). Como consecuencia de esto, concretamente, de una revalorización de la cultura escrita en latín, el romance peninsular adquiere, como se ejemplificó más arriba, gran cantidad de cultismos. Junto a estos hay que destacar el caso de los dobletes léxicos ${ }^{12}$, fácilmente identificables, puesto que algunos de los cambios fonéticos estaban ya consumados en parte. Ej.: ánima/ alma; clamar /llamar; mácula / mancha. El s.XIV, a su vez, acentuará la contribución de cultismos. LAPESA (1981:260) señala como causas de la irrupción de este fenómeno, a lo largo de esta centuria, la actividad de la nacientes universidades, la formación de juristas y la actividad de la traducción. He aquí algunos ejemplos: magnánimo, presuntuoso, mutación, solicitud, súbito.

El redescubrimiento gradual de la tradición cultural en latín provocó que la cantidad de préstamos que esta lengua concedió a otras, tales como el francés o el italiano, fuera de envergadura ${ }^{13}$.

El s. XV, por otra parte, comportará una nueva cesura importante en la historia de la cultura, puesto que significa la consolidación del Humanismo, que se había manifestado ya a finales del s. XIV, pero que alcanza su máximo desarrollo durante esta centuria. Su interés por la cultura clásica como reacción contra los rígidos moldes de la escolástica terminó por situar a la cultura latina (y a la griega) como parte central de su objeto de interés. De igual forma, su marcado antropocentrismo lo llevará, permítase el uso de la expresión, a una "globalización" del conocimiento, pero de un conocimiento "made in Europe and for europeans" como después se verá. Por de pronto, lo

\footnotetext{
'Normalmente se suele asociar este fenómeno a formas dobles donde una de ellas es un cultismo latino o griego (cfr. METZLER 2000, s.v. Doublette); sin embargo, también se puede encontrar el mismo fenómeno hasta en las discutidas relaciones léxicas entre el español y el "português sulino" (clr. BUGUEÑO 1999a).

${ }^{13} \mathrm{He}$ aqui, por otra parte, algunos ejemplos de préstamos para el francés: abjection $<1372>$, abjurer $<1327$

[DDM 1990:1495]>, ablation "amputación" <s.XIII>, abolition <1316 [DDM 1990:1413]>. Por último, para tener otro punto de referencia, vale la pena recurrir al italiano. ZINGARELLI (1990) no ofrece lamentablemente referencias cronológicas, sino que senala la condición de cultismo de las palabras cuando corresponde. Asi son "voce dotte" abilità, abigeato 'robo de animales', abisso 'abismo', abitäbile 'habitable',
abolire 'abolir'.
} 
"italiano" surge como paradigma de esta nueva visión del mundo, lo que lingüísticamente se traduce en una serie de préstamos que recibe el romance peninsular. Aquí citan algunos del ámbito comercial: anchoa (NEBRIJA, h.1495), chusma (<1524> COROMINAS, 1973, s.v.), mercante (<s. XV> COROMINAS, 1973, s.v.), mercancia (PALENCIA, 1490), negociante (PALENCIA, 1490). Esta apertura "al mundo" redundará en el incremento del léxico en campos como el de las letras: códice (<1433> COROMINAS, 1973, s.v.), código (PALENCIA, 1490); de la lit.: escritor (<1444> COROMINAS, 1973, s.v.), literatura (PALENCIA, 1490), poema $(<1450>$ COROMINAS, 1973, s.v.), lírico (<1444> COROMINAS, 1973, s.v.); de la medicina: epilepsia (<1494> COROMINAS, 1973, s.v.) epiléptico (PALENCIA, 1490), vómito (<1450> COROMINAS, 1973, s.v.), asma (NEBRIJA, h.1495)b y úlcera (PALENCIA, 1490), así como de los campos léxicos de la zoología y la botánica.

\section{EI español del s. XVI}

\subsection{Sobre la conciencia idiomática en los albores dell s. XVI}

El ocaso del siglo XV bien puede considerarse desde el punto de vista de la evolución del español como un estadio temprano de la realidad idiomática que llamamos "siglo XVI". Los hechos que a continuación se enumerarán son de tal relevancia para la centuria siguiente, que sólo cronológicamente es posible adjudicarlos al s. $X V$. En verdad conforman una sola unidad con la centuria a la cual anteceden. Los diez últimos años del s. XV constituyen la confluencia de cuatro hechos fundamentales, todos los cuales se dan en 1492: primeramente, la toma de Granada, último baluarte musulmán, y con lo cual se sella el proceso de Reconquista; en segundo lugar, el descubrimiento de América y, finalmente, la publicación de NEBRIJA (1492a) y NEBRIJA (1492b), respectivamente. 
Se puede aseverar con toda propiedad que los diez últimos años de este siglo son una señal de la consolidación final que experimenta el español. Constituyen unos verdaderos síntomas de "una madurez" de la lengua. Un buen ejemplo es PALENCIA (1490), que es algo así como una apostilla bilingüe: bien podría decirse que se trata del primer esbozo de un diccionario bilingüe en español (en realidad, la actividad lexicográfica bilingüe siempre tuvo un desarrollo de consideración dentro de la tradición lingüístico-filológica peninsular. A modo de muestra, piénsese, por ejemplo, en las Glosas Silenses y en las Glosas Emilianenses (finales s. X, principio s. XI) ${ }^{14}$; a estos títulos habría que agregar diversos glosarios que circularon a lo largo de la Edad Media, como también otras obras más amplias de carácter léxicoenciclopédico, como el Catholicon (1286) de Johannes dẻ Janua). Sin embargo, la filología hispánica no confiere a PALENCIA (1490) el título de "primer diccionario", pues las glosas en romance sólo pretenden apoyar el registro léxico latino.

El verdadero título de "primer diccionario" le cabe a NEBRIJA (1492a) y a su correlato NEBRIJA (h.1495) - donde figuran los primeros "americanismos": canoa y cacique. En fin, la publicación de la Gramática y de los Vocabularios bien permiten decir que en Nebrija hay un Sprachgefühl ['sentimiento lingüístico'] ${ }^{15}$ respecto de la realidad idiomática que lo rodea. Tradicionalmente se ha conferido a Nebrija el título de "primer gramático" de la lengua castellana. Sin embargo, la crítica más moderna ha relativizado este título, aunque para nada se ha pretendido menoscabar su aporte fundamental a la historiografía lingüistica peninsular. Lo importante es resaltar que a diferencia de las obras lexicográficas anteriores, los Vocabularios de Nebrija evidencian que ya en esa época la lengua castellana es

\footnotetext{
${ }^{14}$ Naturalmente, se trata de trabajos lexicográficos muy "defectuosos" en cuanto a su ordenación macrocstructural, pero al final de cuentas cumplen con el cometido para el cual tueron concebidos: esto es, ofrecen "equivalencias". ${ }^{15}$ La expresión Sprachgefihl ha sido utilizada de manera bastante libre. Para la dificultad que encierra el concepto v. METZLER (2000, s.v.). Lo importante es resaltar que tanto en NEBRIJA (1492b) como después en VALDÉS (1535) hay una percepción muy clara de la lengua que hablan, perfectamente delimitable y definible lanto frente a los modelos ejemplares (i.e., el latín) como frente a las otras lenguas de Europa.
} 
percibida como tal, como una entidad de fisonomía propia. La lucha de las lenguas vernáculas se ha coronado así con la victoria. Ya no se trata de contar con un instrumento lexicográfico que ayude al latín, sino de poseer dos registros léxicos que corresponden a dos entidades idiomáticas perfectamente reconocibles, legítimas y aceptables. "Mutatis mutandis", los Vocabularios de Nebrija no cumplen menos función que la que hoy cumplirían OLD (1968-1976) para el latín o LSJ (1990) para el griego.

Resulta pertinente referirse ahora más "in extenso" a la conciencia lingüística que se evidencia en este momento de manera tan clara en la Península. La publicación de NEBRIJA (1492b) no sólo representa un hito en cuanto a la codificación de un conjunto de hechos metalingüísticos, sino que señala, ante todo, un cambio cualitativo en la percepción y comprensión del fenómeno idiomático en la Península. Como ya se ha comentado anteriormente, en este cuerpo doctrinal hay todo un proceso de legitimación del español. Sin embargo, es necesario destacar una paradoja en todo esto. Por un lado, en NEBRIJA (1492b: 103) hay una conciencia de la realidad idiomática del romance peninsular, al punto que se la concibe y se la siente como una realidad histórica. Esta historicidad, a su vez, es la que lo lleva a querer darle al castellano una gramática ("[un] arte del castellano" en palabras del propio Nebrija). Sin embargo, esta tarea codificadora y normativa no es un objetivo en sí mismo, sino un recurso propedéutico destinado a un mejor aprendizaje del latín (idem: 107). De esta manera, entonces, el castellano termina legitimándose como lengua en el intento de equipararlo al latín. Como es de público conocimiento, en la tradición medieval sólo la lengua que contaba con un cuerpo doctrinal metalingüístico era considerada como una verdadera lengua. En palabras de SCHLIEBEN-LANGE (1993), la redacción de NEBRIJA (1492b: 68) significó para el español "uma passagem da nature para a art". Esta "art", por otro lado, es la que le asegura y le da a la lengua una fisonomía, una estabilidad. Así las lenguas "quedan en una uniformidad" (NEBRIJA, 1492b:105). En 
síntesis, lo que acontece en este momento es la toma de conciencia de la lengua como tal: legítima, independiente, histórica. Será esta conciencia la que la Península (así, este espacio geográfico de unidad político-lingüística) exportará para el resto de Europa ${ }^{16}$. Es este el trasfondo que explica, por otro lado, la validez y el valor de VALDÉS $(1535)^{17}$, independientemente de los sensibles vacíos que su exposición presenta ${ }^{18}$. En este autor hay también una defensa de la lengua vulgar, la que, a diferencia de la latina, se aprende "por el uso común de hablar" (VALDÉS, 1535:8). De igual forma, existe también toda una percepción de una diacronía en el español. De esta manera, entonces, la conciencia del uso, la legitimación metalingüística (=gramática) y la conciencia de la historicidad de la lengua son tres pilares sobre los que se funda la consolidación que experimenta el español en este siglo XVI. Las contribuciones léxicas que recibe la lengua durante esta centuria vienen a constituirse, entonces, en un cuarto pilar en todo este proceso.

El advenimiento del s. XVI marca la expansión político-cultural de España, y como consecuencia de esto, el interés por conocer la lengua castellana aumentó considerablemente. En la práctica ello significó que durante esta centuria hubo una respetable producción de lexicones bilingües. En 1505, Pedro de Alcalá publica Vocabulista arábigo en letra castellana (ár.-esp.); en 1550-53, el diccionario del italiano Ambrosio Calepino (prim.ed. 1502) recibe una nueva edición, donde se incorpora, entre otras lenguas, el español; en 1565 aparece el Vocabulario de los vocablos que más comúnmente se suelen usar, de Jacques de Liaño (esp.-fr.); en 1570, El vocabulario de las lenguas

\footnotetext{
"Según CANO AGUILAR (1992), la unificación política de la Peninsula y la "factura" de un cuerpo doctrinal de la lengua (= gramática) son los dos factores que hacen del español una "lengua de cultura" (se usa esta expresión en un sentido meramente referencial) y que contribuyen para su prestigio fuera de las fronteras nacionales.

${ }^{17}$ En palabras de LAPESA (1981), la exaltación de la lengua vulgar que resulta tan patente en este autor se debe al gusto del Renacimiento por todo lo natural, incluyendo las lenguas vulgares, que se aprenden por el uso, es decir, de manera natural.
}

${ }^{18}$ Cfr. LOPE BLANCH (1990: 78 y ss.) 
toscana y castellana, de Cristóbal de las Casas y en 1599 , el Diccionario bilingüe español-inglés de Percyvall. El s.XVII, por otra parte, representa un aumento de esta tendencia, la que se coronará con el Tesoro de la lengua castellana (1611) de Sebastián de Covarrubias, primer diccionario monolingüe semasiológico, etimológico y enciclopédico del español. Una lista completa de diccionarios de esta época puede hallarse en GILI GAYA (1947).

En cuanto al plano fonológico y gramatical, el s. XVI ya representa en grandes líneas la fisonomía de la lengua española de hoy. En este contexto sólo se comentará el llamado "reajuste fonológico", esto es, el último gran acomodo del sistema fonológico, fenómeno que tiene implicaciones no sólo para la Península, sino que también para el llamado "español americano". Esta nivelación o reajuste había comenzado a gestarse en la segunda mitad del s. XV y alcanza su pleno desarrollo durante el siglo siguiente, caracterizando a grandes zonas de la Península, especialmente a la región sur. Esto es lo que se conoce como "español andaluz". Por la extensión del fenómeno, CATALÁN (1989) prefirió denominarlo de "español atlántico", puesto que este océano baña tales territorios o les sirve como un "espacio común". Tal modalidad lingüistica se hace presente en parte de la Península (zonas centro y sur), las Islas Canarias y la América Hispánica (desde México al sur).

\subsection{Sobre las contribuciones léxicas en el español del s. XVI}

En el plano léxico, el s. XVI representa una amalgama de contribuciones de raigambre muy heterogénea.

De una parte, y como ya se había hecho sentir en el siglo anterior, hay una fuerte contribución léxica de las lenguas clásicas, que se hace más sensible en este período por el franco apogeo de las ideas humanistas. En concreto, el latín representa un manantial inagotable de contribuciones, ya no sólo en campos léxicos tales como el religioso o el administrativo, sino que también en campos léxicos como el 
de la botánica y la medicina. Este s. XVI representa el momento en que la scientia nova intenta abrirse paso ante las innúmeras preguntas y cuestionamientos que ella misma se hace - piénsese, por ejemplo, en el Examen de los ingenios (1583?) del Dr. Juan Huarte de San Juan y en Sobre Dioscórides (1555) del Dr. Andrés Laguna. Como es de suponerse, todo progreso científico es "intertextual", es decir, depende de discursos anteriores, y ésta no será la excepción. Los estudios de medicina, por ejemplo, se apoyarán en la tradición clásica (tanto latina como griega) para luego intentar derivar a formulaciones nuevas. Es ésta la causa de la presencia de tanto cultismo en este siglo.

A continuación se ofrece una lista de términos de botánica: sen (<1518> COROMINAS, 1985:202a [lat. farmacéutico sene?]), celidonia (PALENCIA, 1490 [lat. chelidonia, GEORGES, 1988, s.v.]), genciana (PALENCIA, 1490 [lat. gentiana, GEORGES, 1988,s.v.]), linaloel 'áloe' (CÁRDENAS, 1591 [lat. ligna y aloes; tal vez por conducto del francés]), mejorana (NEBRIJA, h. 1495 [lat. medieval majorana?; KIESLER, 1994: probablemente del árabe mardaquš]), poleo 'planta herbácea' (NEBRIJA, h.1495 [lat. pulejum, GEORGES, 1988, s.v.]), solatro 'planta de la familia de las moráceas' (NEBRIJA, h.1495 [lat. tardío solastrum]), squinanto 'planta perenne' (CÁRDENAS, 1591 [1at. schoenanthus, GEORGES, 1988, s.v.]).

Las contribuciones en el campo de la medicina y la anatomía son igualmente numerosas: astringente 'que constriñe' $(<1578>$ COROMINAS, 1980: 806b [lat. adstringens, GEORGES, 1988, s.v.]), bituminoso 'que contiene bitumen' (CÁRDENAS, 1591 [lat. bituminosus, GEORGES, 1988, s.v.), cálido 'lleno de energía' (CÁRDENAS, 1591 [lat. calidus, GEORGES, 1988, s.v.), calva 'calvicie' (CÁRDENAS, 1591 [lat. calva, GEORGES, 1988, s.v.]), cámaras de sangre 'disentería' (NEBRIJA, h. 1495 [lat.vulgar camara, GEORGES, 1988, s.v.]), coligancia 'relación entre dos partes del cuerpo' (<1555> AUT, 1726 [lat. medieval colligantia, GEORGES, 1988, s.v.]), gula 'garganta'(CÁRDENAS, 1591 [lat. gula, GEORGES, 1988, s.v.]), opilar 'obstruir, cerrar el paso' (<1555> AUT, 1737 [lat. oppilare, GEORGES, 1988, s.v.]). 
Un capítulo aparte merece el tratamiento de las contribuciones del griego. Según la división propuesta por WARTBURG (1952:81 y ss.) es posible hablar de una Romania Occidental y de una Romania Oriental, cuyo eje divisorio sería la línea La Spezia-Rimini. Formando parte de la vertiente oriental se produce en el sur de Italia, antes del tiempo de la romanización, una fuerte influencia griega, que según LAUSBERG $(1969, \S 35)$ adquiere la envergadura de un adstrato. A este adstrato, entonces, se deben las primeras contribuciones de la lengua helénica, por ej., gr. petra > lat. petr $a^{19}$ (que entra en colisión con saxum y doc. ya en Ennio (s. II a.C.)) > esp. piedra; más ejemplos pueden hallarse em MENÉNDEZ PIDAL (1968, §4.2). Ya en la Romania Hispánica, hay contribuciones griegas (préstamos) durante el s. XIII en el campo léxico de la religión (iglesia, liturgia), cuestión a la que se ha hecho referencia ya. En lo que respecta a este segundo tipo de contribución, esto es, a los cultismos griegos, no siempre es fácil determinar si éstos accedieron directamente al castellano desde aquella lengua, adaptándose simplemente a la escritura latina o si hubo otra lengua que sirviera de intermediaria. MESSNER (1979:68) se inclina a creer que los helenismos del s. XV llegan al español a través de los textos latinos, italianos o catalanes. Esta observación la debemos tener presente al pasar revista a los grecismos del s. XVI.

Como ya se ha dicho respecto del latín, el griego y su literatura vuelven a constituirse en una contribución importante para el conocimiento en el s. XVI; en concreto, toda la sabiduría de Platón, Aristóteles y Galeno, por citar sólo algunos, regresa a un primer plano como fundamento teórico para el desarrollo de la scientia nova. Por ello, las contribuciones en los campos léxicos de la medicinal anatomía, la botánica, la zoología y la astronomía constituirán un aporte decisivo al léxico de esta centuria. He aquí algunos ejemplos: atrofia (<1555> COROMINAS, 1985:653a [gr. atrojía ${ }^{20}$, LSJ, 1990,

19Por una limitación en el procesador de textos no ha sido posible marcar la lonicidad en el étimo griego/pétra/ ni la cantidad vocálica breve (marcada con [_] bajo la vocal) en petra.

$20 / \mathrm{a} /$ con spiritus lenis. 
s.v.]), dipsada 'serpiente' (CÁRDENAS, 1591 [gr. diyáV, LSJ, 1990, s.v.; palabra documentada ya en 1275 , pero de uso muy poco frecuente antes s. XVI]), epitimo 'planta parásita' (<1555> COROMINAS, 1985:544a [gr.epiqumoV'1 , LSJ, 1990, s.v.]), eupatorio 'especie de agrimonia' (<1512> BB, 1987:1915 [gr. eupatórion'22, LSJ, 1990, s.v.]), hermodátil 'quitameriendas' (CÁRDENAS, 1591 [gr. ermodaktulo $\mathrm{V}^{23}$, LSJ, 1990, s.v.]), leche de gallina 'planta herbácea de la familia de las liliáceas' $(<1555>$ AUT, 1734 [calco de gr. orniqogalon $^{24}$, LSJ, 1990, s.v.]), quilo 'linfa' (<1583> AUT, 1729 [gr. culó V, LSJ, 1990, s.v.]), zodiaco (PALENCIA, 1490 [gr. xodiakóV, LSJ, 1990, s.v.; COROMINAS, 1992:108b cree que entre el étimo griego y la forma románica media lat. zodiacus; tal propuesta no puede descartarse, principalmente debido a la acentuación paroxítona común al español y al latín, comparada con la acentuación oxítona que presenta el étimo griego]).

Todavía en este siglo aparecen algunos arabismos relativos a los campos léxicos de la botánica y la medicina: alejija 'masa de harina con ajonjolí que se da a los enfermos' (<1570> GILI GAYA, 1947, s.v. [ár. dašî̌sa, COROMINAS, 1980:142a]), jara 'arbusto de la familia de las cistáceas' (NEBRIJA, h.1495 [ár. ša 'ra', KIESLER, 1994, s.v.]), bezahar 'cálculo de algunos animales que se usa como antídoto o medicamento' (<1555> AUT, 1726 [ár. africano bezuwâr, COROMINAS, 1980: 579b]).

En relación a los dobletes, se señalarán sólo tres casos: llama $<1250-80>$ / flama <h.1579-90>; doblar $<1490>$ / duplicar $<1584>$; obra $<$ h.1250>/ opera $<$ fines s. XVI $>$.

Por último, cabe mencionar algunos préstamos del italiano (it.) y del francés (fr.): madrigal (it.), capricho (it.), modelo (it.), carabina (fr.), moda (fr.), paquete (fr.). Un levantamiento bastante repre-

${ }^{21} / \mathrm{e} / \mathrm{con}$ spiritus lenis.

$22 / \mathrm{u} /$ con spiritus lenis.

${ }^{23} / \mathrm{e} / \mathrm{con}$ spiritus asper.

${ }^{24} / 0 /$ con spiritus lenis. 
sentativo de este fenómeno se puede hallar en CANO AGUILAR (1992: 252).

Para el final ha quedado el "caso" de la contribución de las lenguas indígenas americanas, sobre el que tanto relato mitológico se ha escrito. Primeramente, parece necesario puntualizar que la recepción de todo el material que se escribió a lo largo de los cien primeros años tras el Descubrimiento tuvo una muy desigual recepción en el Viejo Mundo ${ }^{25}$. Por ello es que más arriba se habló de un conocimiento "made in Europe and for europeans".

Una motivación "antropológica", como se diría hoy, ciertamente no fue el motor de la empresa del Descubrimiento y la Conquista. Esto significa que la aprehensión lingüística del Nuevo Mundo estuvo condicionada por fuerzas bien concretas: las económicas y las teológicas. Primeramente, los españoles incorporaron vocabulario indígena al español en la medida en que no encontraron para los "realia" respectivos una designación en su lengua. Pero aún así, en muchos casos se recurrió a la paráfrasis o a mecanismos designativos (onomasiología) por contigüidad de forma ${ }^{26}$. De otra parte, la

\footnotetext{
${ }^{25}$ Es necesario destacar, sin embargo, que seria mejor separar entre lo que se ha denominado "recepción" de lo escrito en América y la producción textual que hubo a lo largo del s. XVI. La verdad de las cosas es que esta producción es cuantiosa, sobre todo, aunque no exclusivamente, en lo que se refiere a documentos administrativos. Una bibliografia cuantiosa y representativa de esta fenómeno es la que acopió BB (1987) para su levantamiento léxico. Dicho sea de paso, a pesar de la exhaustividad de BB (1987), todavía hoy existe una gran cantidad de material aún no descubierto u olvidado, el cual puede ayudar a proporcionar una imagen todavía mejor sobre el deasarrollo de la lengua española en América — v., por ejemplo, BALDINGER (1983 y 1992) - De otra parte, hubo hasta una modesta producción literaria durante estos primeros tiempos, como es el caso de Espejo de paciencia (1608), de Silvestre de Balboa Troya y Quesada. (Cir. VALDÉS BERNAL, 1984:9 y ss.). En general, sin embargo, esta producción literaria ofrece resultados bastante modestos -para el caso de Chile, por ejemplo, v. BUGUEÑO (1999b, notas I y 2). Cuantitativamente, son los documentos administrativos y las Crónicas de Indias los grandes exponentes de las producción textual de este siglo.

2"Estos mecanismos se observan, sobre todo, en la designación de flora y fauna. Aqui se ofrecen algunos ejemplos: andullo (varias acs. en DRAE 1992, s.v./ en Cuba: 'pasta de tabaco para mascar', SOPENA 1983, s.v.), anea ('planta de la familia de las tifáceas (...)' DRAE 1992, s.v./'género de lepidópteros diumos de América del Sur (...)' SOPENA 1983, s.v), gallina ('hembra del gallo (...)', DRAE 1992, s.v./ en Colombia 'ave de rapiña', SOPENA 1983, s.v.), madroño ('arbusto de la familia de las cricáceas (...)', DRAE 1992,s.v./ en Centronmérica 'árbol de madera fina' MORINIGO 1996, s.v.). En cuanto a las paráfrasis, baste aqui citar el caso de hierba 'mate' y sus construcciones sintagmáticas: hierba brava, hierba calmante, hierba de la perdiz, hierba del bicho, etc,; para más ejemplos v. SOPENA $(1983$, s.v. $)$.
} 
deșcripción de las lenguas indígenas interesó sólo en la medida que ayudó a la Evangelización. A grandes rasgos (y en orden cronológico), los grupos lingüísticos que los españoles encontraron fueron los siguientes: el arauaco, el náhuatl, el quechua, el aimara, el mapudungum y el (tupí-)guaraní. Por otra parte, todos están desigualmente representados en español y ello en directa proporcionalidad con la importancia o vigor que tenía la respectiva cultura. Debido a esto, por ejemplo, en el español estandard (digamos "español general", aunque no es lo mismo) la presencia de nahuatlismos es superior a la del mapuche, la lengua mapudungum, que se hablaba en gran parte de Chile y la Argentina.

Por otra parte, algunas de las etnias con las que los españoles entraron en contacto desaparecieron rápidamente y no alcanzaron a dejar mucho material lingüístico que pudiera aprovecharse en español.

En consonancia con la impronta "ideológica" del siglo XVI - si es que se puede usar con absoluta propiedad esta palabra - la preocupación inquisitiva del hombre de esta centuria estaba focalizada en la propia tradición. Esto quiere decir que a los europeos sólo les interesaba lo que decía relación con europeos. Las empresas expedicionarias en sí, no constituían sino un esfuerzo por probar lo que la propia tradición había depositado desde tiempos inmemoriales en su sedimento cultural: el Preste Juan o Adán de Bremen no son sino un par de ejemplos de una multitud de historias y leyendas que circularon por Europa desde los tiempos de la Grecia Clásica. Llevado al terreno práctico, lo anterior significa que cuando las primeras expediciones llegaron a América (léase Colón), los indígenas en sí no fueron vistos, o parafraseando a TODOROV (1991), no hubo un encuentro con el "Otro". Fue con esa misma falta de percepción de la "otredad" - permítase el uso de un neologismo - que NEBRIJA (h.1495) incorporó canoa y cacique en su Vocabulario. No obstante que al comenzar el s. XVI ya se sabía en Europa que se había descubierto un nuevo continente, esta actitud persistirá a lo largo de toda la centuria. Ya que, por otra parte, este aspecto de la discusión escapa al objeto de este trabajo, baste señalar solamente que la historia 
de la recepción de las Crónicas de Indias muestra que el interés por las nuevas realidades fue mesurado, para decirlo de alguna manera. Informaciones valiosísimas a este respecto se pueden encontrar en GEWECKE (1992), trabajo que lamentablemente no está traducido todavía al portugués o al español, pero que constituye un texto clave para entender el problema; también conviene tener en cuenta ZEA (1993). Las observaciones precedentes encuentran un aval en el tratamiento que Sebastián de Covarrubias hace de los 23 americanismos que incorpora en el Tesoro de la lengua castellana (1611). LOPE BLANCH (1990) ha hecho un interesante estudio sobre el particular, concluyendo que este lexicógrafo no les prestó mayor atención, como si no hubiera en él una clara conciencia de lo que significaba América. LOPE BLANCH termina su artículo con una interesante obervación: "(...) el mundo americano quedaba todavía un tanto distante y al margen de los intereses científicos de la mayor parte de los eruditos peninsulares" (1990:174).

De otra parte, tampoco se puede aseverar que no hubo ningún interés por las lenguas indígenas. En este sentido, ejemplares son los esfuerzos de los misioneros por elaborar gramáticas y diccionarios. Baste citar tan sólo dos trabajos relativos a las llamadas "lenguas generales", esto es, las lenguas que los eclesiásticos concibieron como de importancia mayor y gran extensión. Ya en 1560 el Padre Domingo de Santo Tomás publicaba Lexicón o Vocabulario de la lengua general del Perú, para el quechua, y en 1571, el Padre Alonso de Molina sacaba a la luz pública Vocabulario de la lengua mexicana y castellana para el náhuatl (la versión castellano-mexicana había sido publicada en 1555). Para el guaraní y el mapudungum no es posible ofrecer en este momento sino noticias muy fragmentarias sobre este particular. Para la primera de estas lenguas compuso Antonio Ruiz de Montoya un Arte y Vocabulario de la lengua guarani (Madrid, 1640). El caso del mapudungum, por otra parte, no conoce obras análogas sino a partir del s. XVIII.

En relación al léxico propiamente tal, se ha dicho que su suerte es bastante dispar en cuanto a la resonancia que encontró para 
incorporarse eventualmente al español. Tómese como botón de muestra dos casos opuestos, y por ello mismo, paradigmáticos. En primer lugar, está el taíno, perteneciente al grupo arauaco, lengua que se hablaba en gran parte de las islas del Caribe, junto a la lengua de igual nombre. De una contribución de envergadura del taíno no se puede hablar en español, no obstante que estas mismas islas sirvieron por más de treinta años de base a las expediciones que se dedicaron a explorar el continente, como puede leerse tanto en Cortés - Bernal Díaz (sin mencionar a Colón). La razón de esta escasa representativi-dad no se debe exclusivamente a la depredación de los descubridores (como las Casas voyeristamente relata), sino que a también a problemas de "salud pública": los indios no conocían ni el resfrío ni la gonorrea ("importados" por los españoles), de tal manera que su sistema inmunológico colapsó rápidamente ${ }^{27}$. A ello hay que agregar la profunda depresión colectiva que los afectó también por el hecho de tener que trabajar en condiciones infrahumanas, cosa que fue muy sensible entre las mujeres y los niños.

De origen taíno ${ }^{28}$ son palabras pertenecientes a los campos de la botánica y la zoología, tales como arcabuco 'bosque espeso en la montaña o el llano' (<1515> BB, 1987:354)29, caimán $(<1530>$ COROMINAS, 1980: 739a), guayaba (<1532> BB, 1987:2156), guayacán (<1532>, COROMINAS, 1980:255a [taíno waiacan,

\footnotetext{
${ }^{27}$ Una buena síntésis de cste problema puede hallarse cn GUTIÉRREZ (1985:30 y ss.)

${ }^{28}$ Resulta necesario aclarar que el registro léxico con contribuciones de las diferentes lenguas indigenas que se entregará a continuación para nada mencionará ni se referirá a la extensión de uso de las palabras en todo el continente americano o en la Península. Aqui simplemente se enumera una serie de palabras que se han incorporado al español, así a secas (es decir, el español como sistema, con independencia de una consideración de sus diferentes normas, que constituyen los "locos" reales donde cabe hacer imputaciones de uso. Para consideraciones teóricas a este respecto v. RONA (1969); aplicaciones prácticas de este principio, por otro lado, se pueden encontrar en HAENSCH (1987). La real distribución y uso de los préstamos de las lenguas indigenas en todas o en algunas modalidades del diasistema del español es un capítulo que la (neta)lexicografia hispánica todavía está por escribir. Para más detalles sobre esta cuestión v. MORENO DE ALBA (1992); también es muy provechosa la lectura de FERRECCIO (1978).

${ }_{29}^{2}$ Para muchas etimologias del arauaco, los filólogos arriesgan sólo la imputación geolingúistica. En este trabajo sólo se incluyó alguna etimologia en aquellos casos en que se consideró que la propuesta presenta
algún grado de plausibilidad.
} 
DRAE, 1992, s.v.]), maguey (<1515> COROMINAS, 1980:768b) y nigua 'insecto díptero' (<1526> COROMINAS, 1981:227b). A estas palabras hay que agregar otras como cacique (NEBRIJA, h.1495), cazabe 'torta que se hace de maíz' $(<$ h.1492> COROMINAS, 1980: 932b [taíno caçabi, GÓMEZ DA SILVA, 1995, s.v.]), aji (<1493> COROMINAS, 1973 [taíno ashi, GÓMEZ DA SILVA, 1995, s.v.]) y canibal, cuya etimología ha sido objeto de larga discusión. Modernamente, se acepta que su origen está ligado a la palabra caribe - cariba, pues, a lo que parece, esta tribu era efectivamente antropófaga.

Al otro extremo se ubica la fuerte contribución del náhuatl (náh.), la lengua que se habla en México-Tenochtitlan a la llegada de Cortés (1521). La importancia económica y religiosa que tuvo la región se deja sentir en la pronta codificación que tuvo esta lengua indígena. Hacia 1550 el Padre Bernardino de Sahagún, un verdadero etnógrafo ("rara avis"en aquellos tiempos) había ya procurado un sistema de transcripción del náhuatl en caracteres latinos, sistema que enseñó a los niños indígenas para que éstos pusieran por escrito las tradiciones de su pueblo. Este "institución cultural" ha pasado a la historia como la Escuela de Traductores de Tlatelolco. El mérito de redactar un diccionario, eso sí, le corresponde a Molina, como se ha señalado ya. En consonancia con lo que se ha expresado hasta aquí, los campos léxicos más favorecidos para incorporarse como préstamos al español son los de la flora y la fauna. Aquí daremos algunos ejemplos: achiote 'bija' (MOLINA, 1571 [náh. achiotl, SIMÉNON, 1994, s.v.], capuli 'árbol de las rosáceas' (MOLINA, 1571 [náh. capulin SIMÉNON, 1994, s.v.]), chile 'aji' (MOLINA, 1571 [náh. chilli, SIMÉNON, 1994, s.v.]), elote 'mazorca tierna de maíz' (<1546> BB, 1987: 1637 [náh. elotl, SIMÉNON, 1994, s.v.]), exquiatole 'variedad de atole' (CÁRDENAS, 1591 [náh. comp. de izquitl+atulli; SIMÉNON, 1994, s.v.]), guamuchil 'fruto comestible de un árbol de las leguminosas' (<1532> BB, 1987:2143 [náh. quamochitl, SIMÉNON, 1994, s.v.]), jocote 'árbol que produce una especie de ciruela muy ácida' (MOLINA, 1571 [náh. xocotl, SIMÉNON, 1994, s.v.]), tlacuache 
'marsupial didálgico, especie de zarigüella' (MOLINA, 1571 [náh. tlacuatzin, SIMÉNON, 1994, s.v.]). A estas palabras habría que agregar otras contribuciones tales como cocoliste 'cualquier enfermedad epidémica' (<1577> BB, 1987:951 [náh. cocoliztli, SIMÉNON, 1994, s.v.]), comal 'vasija de greda' (<1532> BB, 1987:982 [náh. comalli, SIMÉNON, 1994, s.v.]).

En relación a la contribución de otras lenguas, considérense los siguientes ejemplos. Tres quechuismos (que.) conocidos: coca (<1543> BB, 1987:946 [que. kuka, LARA, 1991, s.v.]) cóndor (<h.1554> COROMINAS, 1973, s.v. [que. kuntur, LARA, 1991, s.v.]), papa (<h.1540> COROMINAS, 1973, s.v. [que. papa, LARA, 1991, s.v.]). En lo que respecta a la lengua mapuche, se ofrecen también tres palabras emblemáticas: quillay (<s. XVII> [map. küllai, AUGUSTA, 1991, s.v.]), copihue 'planta de tallo voluble, de la familia de las liliáceas, originaria del sur de Chile' (<s. XVII> [map. kopiwe, AUGUSTA, 1991, s.v.]), boldo 'arbusto de la familia de las monimiáceas, originario de Chile' (<s. XVII> [map. fol $\cdot o$, AUGUSTA,1991, s.v.]). Finalmente, de origen tupí son: ananás $(<1578>$ (raro antes s. XIX) COROMINAS, 1973, s.v. [(port.) tupi na'na, DA CUNHA, 1998, s.v.]) $)^{30}$, yacaré (<s.XVI> [(port.) tupí iaka're, DA CUNHA, 1998, s.v.]), mandioca (<1536> COROMINAS, 1973, s.v. [(port.) tupí mani'oka, DA CUNHA, 1998, s.v.]).

Al iniciar este apartado sobre las voces amerindias se ha señalado que en muchos casos los españoles recurrieron a la paráfrasis o a la sinonimia. He aquí algunos ejemplos que complementan la nota n.25: "los xocotes o manzanillas de la tierra", "cierta pucha o atole", "la yuca, que es una raiz de que hacen el pan de caçaue", "el mecasuchil, que no es otra cosa sino unos palitos o hebritas verdes y delgadas".

\footnotetext{
".1"En el caso de los tupismos hay indicios que permiten concluir que éstos han entrado al español por intermedio del portugués. Por ello es que la notación etimológica incluyó entre paréntesis este hecho [(port.)]. Sin embargo, no debe descartarse del todo que la "Guarania portentosa" que es el Paraguay pueda haber permitido un contacto
directo entre el tupí y el español.
} 
Para el final ha quedado el problema de las palabras de origen romance, pero atestiguadas por primera vez en la América Hispana. En realidad, cuando se aborda el problema de la contribución americana al español, debiera hacerse distinción entre "indoamericanismos" y "americanismos romances", para decirlo de alguna manera. A este último grupo pertenecen cachupin "mote que se aplicaba al español que pasaba a América' $\langle$ h.1580 $>$, chapetón 'español recién llegado a América' $\langle$ h.1546>, dejativo 'amodorrante' $<$ h.1576>, desazogadera $<1589>$, encorporadero 'sitio donde se hace la incorporación del azogue' <1591>, herido 'canal o conducto de un río' $<1591>$.

\begin{abstract}
RESUMO: No percurso da história do espanhol, o século XVI marca un momento de importância vital para o desnvolvimento dessa língua. Consumados a maioria dos câmbios fonéticos, a língua espanhola experimenta durante o século XVI uma forte contribuição de origens muito diversas (das línguas clássicas, das línguas ameríndias e de outras línguas românicas).
\end{abstract}

\title{
Bibliografía
}

AUGUSTA, Fray Félix José de. Diccionario araucano:mapuche-español/españolmapuche ${ }^{2}$. Temuco: Editorial Kushe, 1991.

AUT. Real Academia Española de la Lengua. Diccionario de Autoridades (ed. facsimilar), 1726-1739. Madrid: Gredos, 1963.

BALDINGER, Kurt. La formación de los dominios lingüísticos en la Penisula lbérica? ${ }^{2}$. Madrid: Editorial Gredos, 1972.

. Vocabulario de Cieza de León:contribución a la historia de la lengua española en el Perú del siglo XVI, en Lexis (VII,1), p. 1-133, Lima, 1983.

. Nouvelles certaines des isles du Peru (Lyon 1534): édition et commentaire, en Revue de linguistique romane, 56, p. 439-473, Strasbourg, 1992.

.[Nachruf für] Johannes Hubschmid (1916-1995), en Zeitschrift fïr romanische Philologie, (111), p. 777-785, Tübingen, 1995.

$\mathrm{BB}$, Peter. Léxico hispanoamericano del siglo XVI 2 , The Hispanic Seminary of Medieval Studies, Madison, 1987. 
BUBMANN, Hadumod. Lexikon der Sprachwissenschaft ${ }^{2}$. Stuttgart: Alfred Kröner Verlag, 1990.

CANO AGUILAR, Rafael . El español a través de los tiempos ${ }^{2}$. Madrid: ArcoLibros, 1992.

CÁRDENAS, Félix Bugueño Miranda. Algumas considerações preliminares para um levantamento de empréstimos do espanhol no português. In: Atas do III Seminário do Projeto para a História do Português Brasileiro, Instituto de Estudos da Linguagem, UNICAMP [em curso de publicação], 1999a.

. O criollismo chileno. In: Atas do III Seminário internacional de história da literatura, Curso de Pós-graduação em Letras, PUC-RS [em curso de publicação], 1999b.

. El vocabulario de "Problemas y secretos maravillosos de las Indias" del Dr: Juan de Cárdenas (1591). Heidelberg: Inaugural-Dissertation; 1993.

CATALÁN, Diego. Génesis del español atlántico (ondas varias a través del océano), en id. El español: origenes de su diversidad. Madrid: Paraninfo, p. 119-126, 1989.

COD. The concise Oxford Dictionary of current english ${ }^{9}$. Oxford: Claredon Press, 1995.

COROMINAS, Joan. Breve diccionario etimológico de la lengua castellana ${ }^{3}$. Madrid: Gredos, 1973.

- Diccionario crítico etimológico castellano e hispánico (con la colaboración de José Alberto Pascual). Madrid: Gredos ${ }^{2} 1980$ (I), ${ }^{2} 1980$ (II), ${ }^{2} 1980$ (III), ${ }^{2} 1981$ (IV), ${ }^{2} 1985$ (V), ${ }^{2} 1992$ (VI).

DA CUNHA, Antônio Geraldo. Dicionário histórico das palavras portuguesas de origem tupi $i^{4}$. São Paulo: Melhoramentos/Editora UnB, 1998.

DAWABE, Elias Dawabe Elik. Diccionario.Palabras castellanas de origen árabe. Santiago de Chile: Universitaria, 1973.

DAUZAT, Albert, DUBOIS, Jean, MITTERAND, Henri. Nouveau dictionnaire étymologique et historique. Paris: Larousse, 1990.

DOZY, R., ENGELMANN, W.H. Glossaire des mots espagnols et portugais dérivés de l'arabe ${ }^{2}$. Amsterdam: Oriental Press, 1965.

DRAE. Real Academia Española. Diccionario de la lengua española ${ }^{21}$. Madrid: Espasa-Calpe, 1992.

EGUILAZ, L. de Eguilaz y Yaguas. Glosario etimológico de las palabras españolas (castellanas, catalanas, gallegas, mallorquinas, portuguesas, valencianas y 
vascas) de origen oriental (árabe, hebreo, malayo, persa y turco). Granada, s.e., 1886.

ENTWISTLE, William J. Las lenguas de España:castellano, catalán, vasco y gallego-portugués ${ }^{4}$. Madrid: Istmo, 1982.

FERRECCIO, Mario Ferreccio Podestá. El diccionario académico de americanismos. Pautas para un examen integral del Diccionario de la lengua española de la Real Academia Española. Santiago de Chile: Universitaria, 1978.

GEORGES, Karl Ernst. Lateinisch-Deutsches Handwörterbuch ${ }^{8}$. Darmstadt: WBG, 1988.

GEWECKE, Frauke. Wie die nene Welt in die alte kam. Sttutgart: Klett, 1992.

GILI GAYA, Samue!. Tesoro lexicográfico (1492-1726). Madrid: CSIC, tomo I:A-E, 1947.

GÓMEZ DA SILVA, Guido. Breve diccionario etimológico de la lengua española. México D.F.: Fondo de Cultura Económica, 1995.

GUTIÉRREZ, F. Gutiérrez Contreras. América a través de sus códices y cronistas. Madrid: Salvat, 1985.

HAENSCH, Günther. La lexicografia hispanoamericana entre la teoria y la práctica, in Humberto López Morales y María Vaquero (eds.), Actas del I Congreso Internacional sobre el español de América, p. 555-577. San Juan de Puerto Rico, 1987.

HUBSCHMID, Johannes. Vorindogermanische und indogermanische Substratwörter in den romanischen Sprachen. Methodische Überlegungen und Forschungsergebnisse, in Akten des 5. Symposiums über Sprachkontakte in Europa (hrsg. von P. Sture Ureland), p. 241-262. Max Niemayer Verlag, Tübingen, 1982.

ILARI, Rodolfo. Lingüistica românica². São Paulo: Atica, 1997.

KIESLER, Reinhard. Kleines vergleichendes Wörterbuch der Arabismen im Iberoromanischen und Italienischen. Tübingen und Basel: Francke Verlag, 1994.

LAPESA, Rafael Lapesa Melgar. Historia de la lengua española ${ }^{9}$. Madrid: Gredos, 1981.

LARA, Jesús. Diccionario qhechwa-castellano/castellano-qhechwa ${ }^{3}$. La Paz: Editorial "Los amigos del libro", 1991.

LAUSBERG, Heinrich. Romanische Sprachwissenschaft ${ }^{3}$ (I/II), Berlin: Walter de Gruyter, 1969. [hay trad.port.: Lingüística Românica, Calouste-Gulbenkian, Lisboa, s.f.] 
LOPE BLANCH, Juan Manuel. El Diálogo de la lengua de Juan de Valdés, in id. Estudios de historia lingüistica hispánica. Madrid: ArcoLibros, 1990, p. 69-102. - Los indoamericanismos en el Tesoro de Covarrubias, in id. Estudios de historia lingüistica hispánica. Madrid: ArcoLibros, p. 153-174.

LSJ, LIDDELL, Henry George, SCOTT, Robert, JONES, Henry Stuart. A GreekEnglish Lexicon ${ }^{9}$. Oxford: Claredon Press, 1990.

LÜDTKE, Helmut. Historia del léxico románico. Madrid: Gredos, 1974.

MACKENSEN, Lutz. Ursprung der Wörter: Etymologisches Wörterbuch der deutschen Sprache. Frankfurt am Main/Berlin: Ullstein, 1988.

MĖNÉNDEZ PIDAL, Ramón. Manual de gramática histórica española ${ }^{13}$. Madrid: Espasa-Calpe, 1968.

MESSNER, Dieter. Geschichte des spanischen Wortschatzes: eine chronologischetymologische Einführung. Heidelberg:. Carl Winter, 1979.

METZLER. Metzler Lexikon Sprache ${ }^{2}$ (hrsg. von Helmut Glück). Stuttgart/Weimer: J.B.Metzler, 2000.

MORENO DE ALBA, José G. El nuevo diccionario académico, in id. Minucias del lenguaje. México D.F.: Fondo de Cultura Económica, 1992, p. 134-147.

MORÍNIGO, Marcos A. Diccionario del español de América ${ }^{2}$. Madrid: Anaya \& Mario Muchnik, 1996.

NEBRIJA, Elio Antonio de. Lexicon hoc est dictionarium ex sermone Latino in Hispaniensem (1492a), ed. facsimilar, Madrid: Real Academia Española, 1951. - Gramática castellana (1492b)/ introducción y notas de Miguel Ángel Esparza y Ramón Sarmiento. Madrid: Fundación Antonio de Nebrija, 1992. . Vocabulario Español-Latino (h.1495), ed. facsimilar. Madrid: Real Academia Española, 1951.

OLD, P.G.W. Glawe. Oxford Latin Dictionary. Oxford: Oxford University Press, 19681976.

PALENCIA, Alfonso de. Universal Vocabulario: registro de voces internas (1490)/ ed. de John M. Hill. Madrid: Real Academia Española, 1957.

PENNY, Ralph.Gramática histórica del español. Barcelona: Ariel, 1992.

PFISTER, Max. Konzeption und Gestaltung des Lessico Elimologico Italiano (LEI), in Alfred Bammesberger (Hrsg.), Das etymologische Wörterbuch. Firiedrich Pustet, Regensburg (Eichstätter Beiträge, Band 8. Abt. Sprache und Literatur), p. 201$215,1983$. 
PIANIGIANI, Ottorino. Vocabolario etimologico: edizione aggiornata ${ }^{3}$. La Spezia: Fratelli Melita, 1990.

PROB. Le nouveau Petit Robert: dictionnaire alphabétique et analogique de la langue française. París: Dictionnaires Le Robert, 1993.

RONA, José Pedro. Qué es um americanismo?, in El Simposio de México (Actas, informes y comunicaciones del PILEI), p. 135-148. México D.F: UNAM, 1969.

SCHLIEBEN-LANGE, Brigitte. Como podemos escrever uma história das línguas minoritárias? Reflexões sobre a 'Decadence' e a 'Renaissance' do ocitano e do catalão, in id. História do falar e história da lingüistica. p. 65-79. Campinas: Editora UNICAMP, 1993.

SIMÉON, Rémi. Diccionario de la lengua náhuatl o mexicana ${ }^{13}$. S.XXI, México D.F., 1994.

SOLÁ-SOLÉ, J.M. El artículo al- en los arabismos del iberorrománico, in Romance Philology (XXI,3), Berkeley, p. 275-285, 1968.

SOPENA. Americanismos:diccionario ilustrado Sopena. Barcelona: Ramón Sopena, 1983.

VÄÄNÄNEN, Veikko. Introducción al latin vulgar. Madrid: Gredos, 1975.

VALDÉS, Juan de. Diálogo de la lengua (1535)/ ed. de José F. Montecinos. Madrid: Espasa-Calpe, 1976.

VALDÉS BERNAL, Sergio. Los indoamericanismos en la poesia cubana de los siglos XVII, XVIII Y XIX. La Habana: Editorial de Ciencias Sociales, 1984.

WARTBURG, Walther von. La fragmentación lingiïistica de la Romania. Madrid: Gredos, 1952.

WINCKELMANN, Otto, BraISCH, Maria (Hrsgn.). Festschrift für Johannes Hubschmid zum 65. Geburstag, Bern und München: Francke Verlag, 1982.

ZEA, Leopoldo (comp.). Sentido y proyección de la Conquista. México D.F.: Fondo de Cultura Económica, 1993.

ZINGARELLI, Nicola. Vocabolario della lingua italiana". Roma: Zanichelli, 1990. 